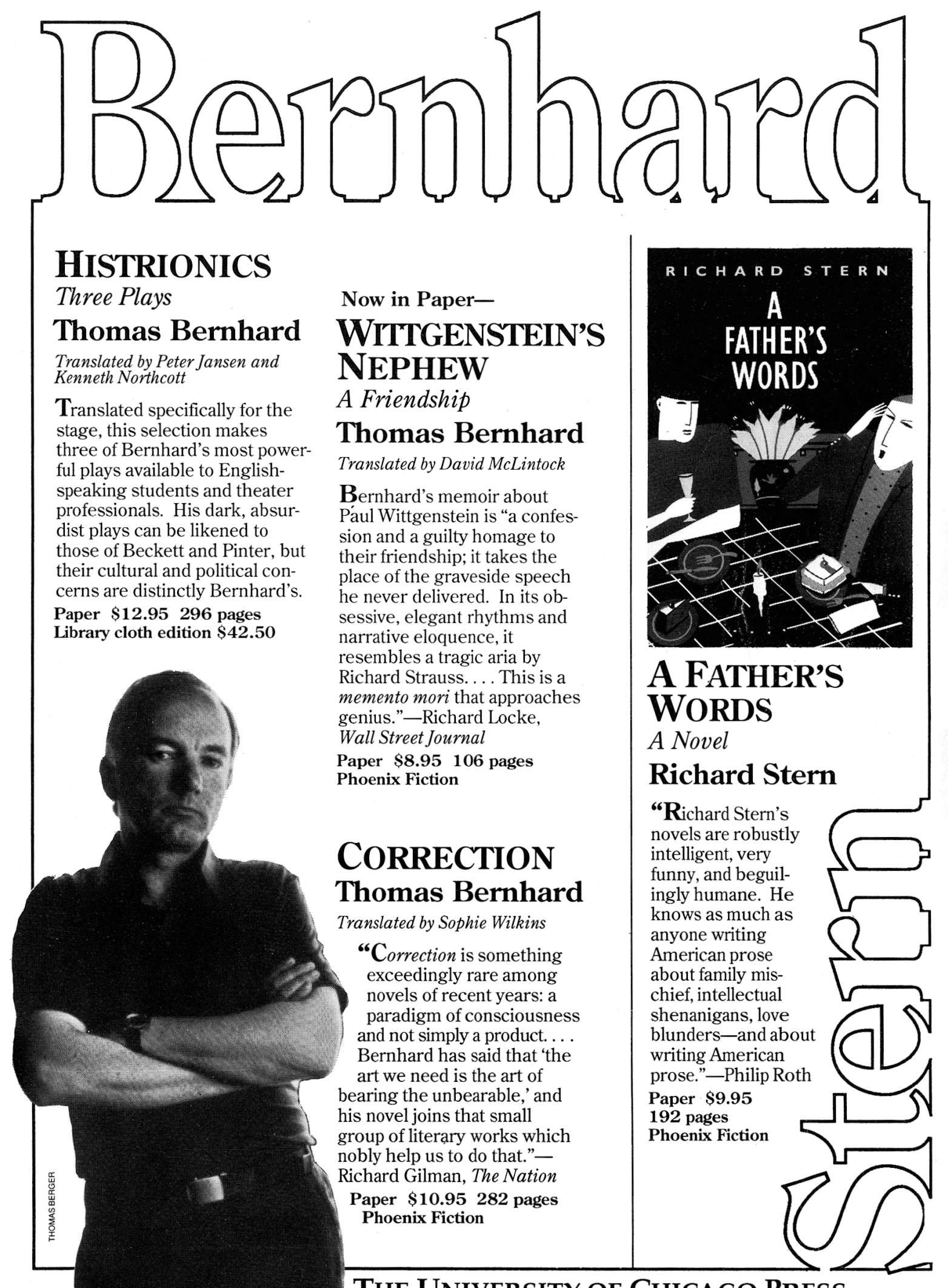

The UNIVERSITY OF CHICAGo PRESS

5801 South Ellis Avenue Chicago, IL 60637 
THE TELEPHONE

BOOK

Technology

Schizophrenia

Electric Speech

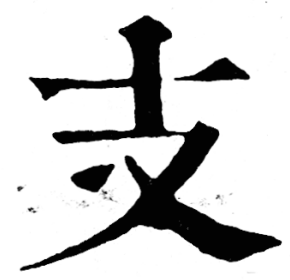

By Avital Ronell

"With The Telephone Book, the deconstruction of 'phonocentrism' takes an unheard-of turn: Heidegger and Derrida are joined by Alexander Graham ("Ma") Bell in a party line that leaves one's ears (and eyes) ringing." - Samuel Weber, International Operator. In many ways a meditation on the technologically constituted state, The Telephone Book opens a new field, becoming the first political

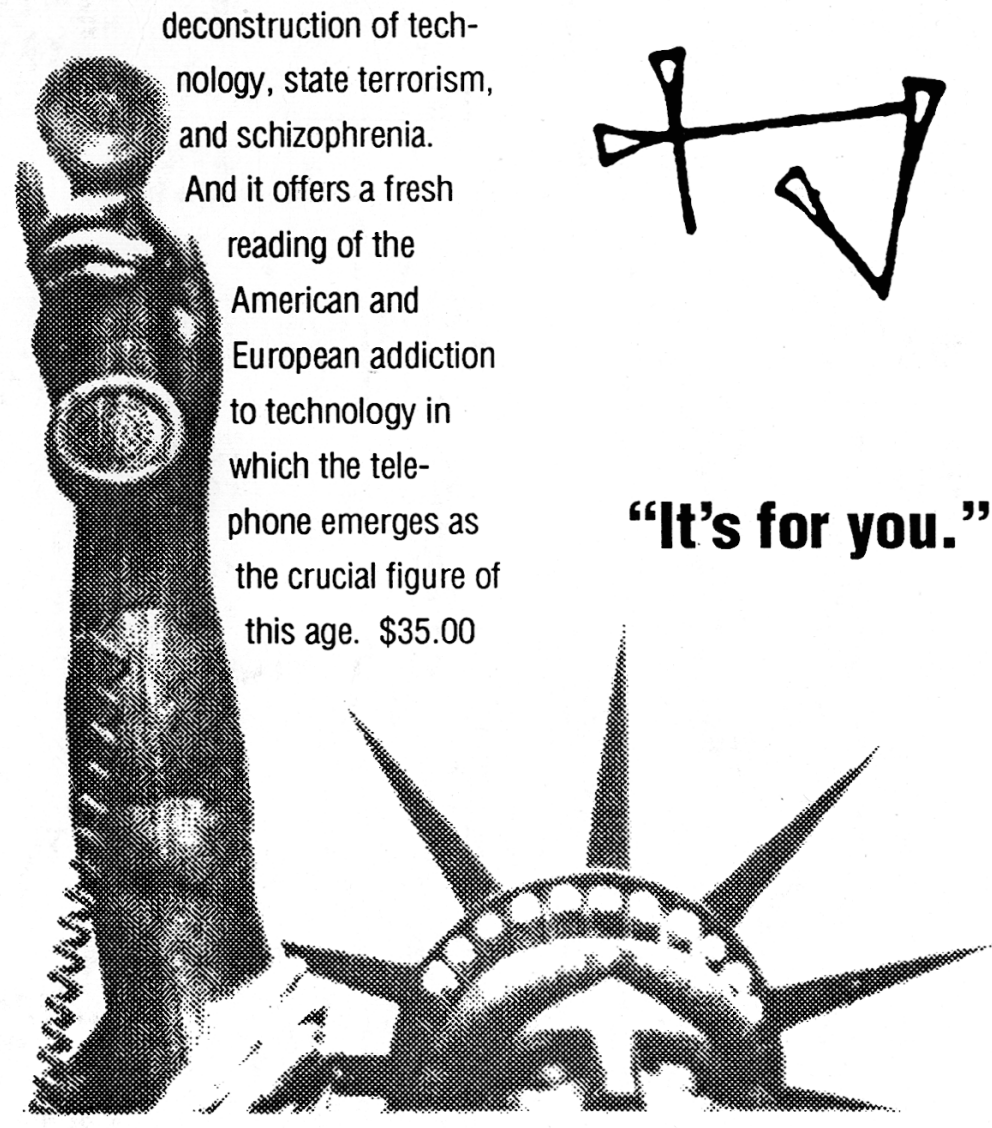

\section{THE ORIGINS OF WRITING}

Edited by Wayne M. Senner

Long shrouded in myth and speculation, the origins of writing have only recently been freed from racial and national bias to become a subject of careful objective study. Historians, linguists, and archaeologists have accumulated abundant new information about the development and spread of writing systems, but until now no single book has attempted to survey and compare the evidence, theories, and conclusions emerging from the various specialties. In The Origins of Writing leading American scholars present the essential story of how and why the world's major writing systems in the Middle East, the Far East, Europe, and Central America came into existence. It will be welcomed by all readers who seek to understand civilization's debt to writing. $\$ 35.00$

\section{NEBRASKA}

University of Nebraska Press $901 \mathrm{~N} 17$ - Lincoln 68588.0520 